\title{
Risk Factors of Childhood Cancer in Armenia: A Case-Control Study
}

\author{
Manushak Avagyan $^{1}$, Lusine Abrahamyan ${ }^{2}$, and Anahit Demirchyan ${ }^{1}$ \\ ${ }^{1}$ American University of Armenia \\ ${ }^{2}$ Toronto General Research Institute
}

October 6, 2021

\begin{abstract}
Background: Childhood cancer (CC) is a leading cause of death among children aged 0-19 years worldwide. Each year, 400,000 new cases of $\mathrm{CC}$ are diagnosed globally. Given the between-country differences in CC incidence rates, types and trends, this study aimed to identify possible risk factors for CC in Armenia. Methods: We used a case-control study design by enrolling participants from the only specialized pediatric hematology and oncology center in Armenia. Cases included patients [?]14 years old diagnosed and treated with a malignant disease between 2017-2020 in the centre. Controls included patients diagnosed and treated in the center during the same period for a non-malignant disease. We conducted telephone interviews with mothers of cases and controls. Independent risk factors of cancer were identified using multivariable logistic regression analysis. Results: Overall, 234 participants (117 cases, 117 controls) were included in the study. Based on the fitted model, maternal usage of folic acid during pregnancy was protective against $\mathrm{CC}$, almost twice decreasing its odds (OR=0.54; 95\% CI: 0.31-0.94). On the contrary, experiencing horrifying/terrifying event(s) during pregnancy (OR=2.19; 95\% CI: 1.18-4.07) and having induced abortions before getting pregnant with the given child $(\mathrm{OR}=2.94 ; 95 \% \mathrm{CI}$ : 1.45-5.96) were associated with higher odds for a child to develop cancer. Conclusion: This study identified three important modifiable risk factors for CC in Armenia, all related to the period of pregnancy. The findings indicate the importance of education on stress reduction during pregnancy, the use of folic acid prior to and during pregnancy, and avoidance of induced abortions.
\end{abstract}

\section{Hosted file}

Risk Factors of Childhood Cancer in Armenia_PBC.docx available at https://authorea.com/users/ 439826/articles/540643-risk-factors-of-childhood-cancer-in-armenia-a-case-control-study

\section{Hosted file}

Tables.docx available at https://authorea.com/users/439826/articles/540643-risk-factors-ofchildhood-cancer-in-armenia-a-case-control-study 


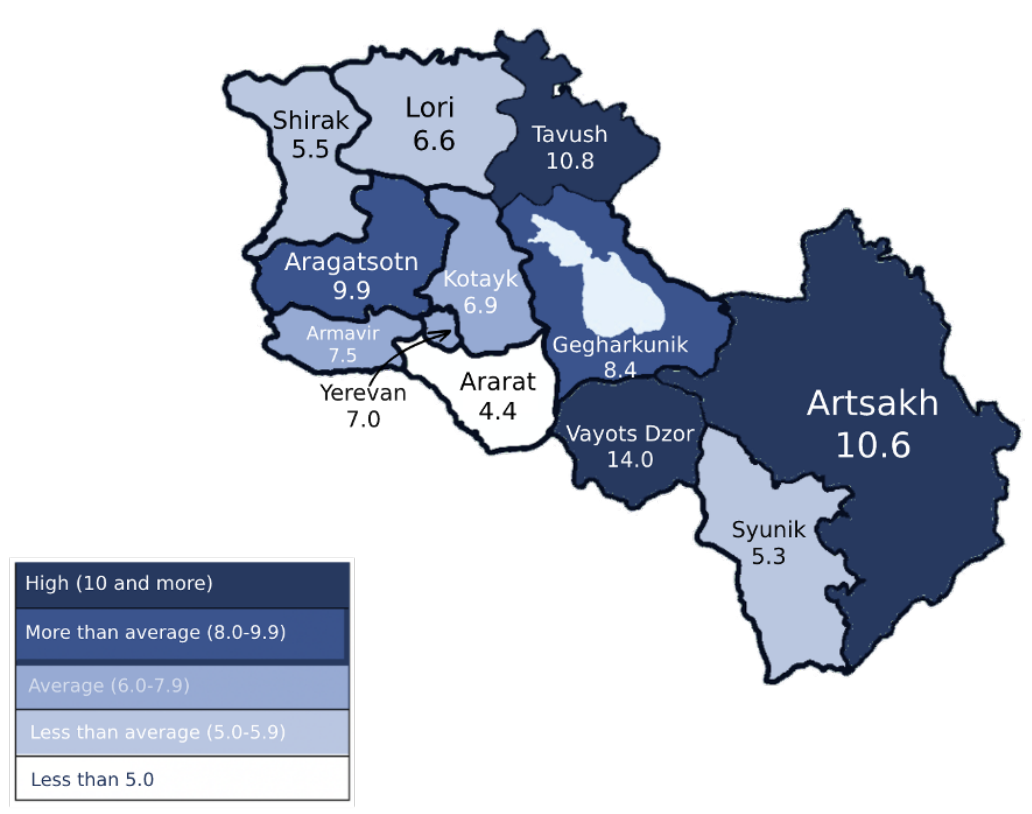

